\title{
EDITORIAL DE APRESENTAÇÃO
}

\section{LOGEION: FILOSOFIA DA INFORMAÇÃO}

Embora as pressões para tornar mais ágil e precisa a recuperação da informação em ciência e tecnologia remontem à primeira metade do século $\mathrm{XX}$, pode-se dizer que a emergência da informação enquanto objeto da ciência se assenta numa conjunção de condições de possibilidades no período pós-guerras.

No âmbito econômico-político, a guerra fria e suas disputas tecno-beligerantes e os modelos de desenvolvimento econômico, alavancados por inovações tecnológicas, colocariam a gestão da informação "para" e "sobre" a ciência e tecnologia como um interesse de Estado. No âmbito teórico, concepções avançaram sobre a modelação da informação e da comunicação, como o aporte sistêmico da Cibernética de Norbert Wiener, a Teoria Matemática da Comunicação e da Informação de Claude Shannon, a Arquitetura de Von Neumann, as ambições visionárias do Memex de Vannervar Bush e de contribuições de outros, participantes das Conferências Macy entre 1946 e 1953. Em 1956, o encontro de Dartmouth para Inteligência Artificial, considerado marco fundador dos estudos das Ciências Cognitivas, avançaria na modelação dos processos cognitivos, onde informação aparece, numa analogia, como resultado do processamento mental de um humano e como resultado do processamento de dados em computadores (JESUÍNO, 2000, p. 316).

A informação, enquanto objeto de estudo da ciência, foi inicialmente construída como manipulável por cálculos, transferível por códigos, acumulável em memórias artificiais, e em seguida assimilável ao humano enquanto maquinismo de processamento envolvendo a linguagem, seus conceitos e regras de dedução e criação. Esta construção atravessaria com certa hegemonia os campos das ciências humanas e sociais interessados no fenômeno informacional.

A emergência da Ciência da Informação é indissociável destes marcos, como ciência social constituída partir de estudos já tradicionais e estabelecidos de recuperação da informação para ciência e tecnologia, especialmente da Documentação, aliados às novas teorias, tecnologias e entendimentos da informação, aplicados ao contexto da comunicação científica.

Foi nos anos 1970 que o atual IBICT deu o passo que institucionalizaria a Ciência da Informação no Brasil, criando no país o primeiro mestrado no campo. Naquele período, a busca por tratamento e direcionamento veloz e adequado da informação "para" e "sobre" 


\section{EDITORIAL DE APRESENTAÇÃO}

ciência e tecnologia alavancou a estruturação e expansão dos estudos da Ciência da Informação pelo globo, do qual o caso brasileiro é exemplar.

O foco na construção de soluções e facilitações do trabalho com informação esteve, desde o início da Ciência da Informação, atrelado à reflexão teórico-conceitual dos fenômenos entendidos como centrais para o campo e na busca de um modelo para guiar a construção de instrumentos de organização e acesso à informação. E embora o conceito de informação tenha inicialmente se balizado por estas concepções teóricas de grande repercussão, a pergunta pela informação e seus fenômenos relacionados nunca esteve fora de sua agenda. Propostas de discussão multidisciplinares, como as promovidas nas edições de Machlup e Mansfield (1983), Kornwachs e Jacoby (1996 citado por CAPURRO, 2007) e Hofkirchner (1999), foram indícios manifestos de demanda por novas respostas.

No final do século XX, o acesso remoto proporcionaria novas perspectivas das práticas informacionais, ao dar visibilidade e amplificar diversos modos de uso, de apropriação e de produção de informação. A relevância e o estatuto da informação em todas as esferas da vida é algo hoje corrente no senso comum, o que González de Gómez (2001) já apontara como passagem de um regime de verdade a um regime de informação.

A pergunta sobre a informação para além da ciência e tecnologia e dos Sistemas de Recuperação da Informação foi também a abertura de novas perspectivas que iriam da “informação para os humanos” em direção aos "humanos na informação".

Se o aporte cognitivo na Ciência da Informação visava o processamento humano na construção da informação, as abordagens chamadas sociais recolocariam este humano em seus contextos sociais e culturais, inseridos em suas práticas cotidianas, no seu fundamental modo de ser junto com os outros. Alargaram-se as indagações sobre o informacional e o escopo teórico chamado para sua compreensão, especialmente de teorias geradas no entrelaçamento entre a Filosofia e as Ciências Humanas e Sociais em que a linguagem tem centralidade. Para além de um ordenamento da informação pergunta-se também sobre suas condições de produção, os modos de sua apropriação, seu uso nas aprendizagens contemporâneas e seu papel nas construções sociais da realidade.

Neste cenário abriu-se com mais contundência as indagações filosóficas sobre a informação em questões epistemológicas, ontológicas, éticas e políticas, num tempo de mudanças institucionais, de web e redes sociais, de gestão do conhecimento, de ensino e cirurgias a distância, e de inúmeros meios informáticos indissociáveis da informação, seu uso e suas repercussões na vida, ambiente e sociabilidade humanas. 


\section{EDITORIAL DE APRESENTAÇÃO}

O grupo de pesquisa Filosofia e Política da Informação do IBICT, desde sua criação em 2009, desenvolve agenda de pesquisas que "faz questão", no duplo sentido deste termo, da informação em seus usos sociais, na perspectiva das filosofias da práxis. A partir de 2010 ampliou sua interlocução com outros pesquisadores com a realização anual do Colóquio Habermas, no IBICT. Hoje o grupo de pesquisa considera a oportunidade na Ciência da Informação de expansão da interlocução entre aportes filosóficos com perspectivas do informacional. A revista "Logeion: Filosofia de Informação", instalada no IBICT, quer abrir espaço para dar lugar de destaque aos diversos logoi, ser um LOGEION daquilo do que "faz questão", a informação, para trabalhos que se inclinem a uma filosofia da informação.

O lançamento da "Logeion: Filosofia da Informação" é possível por contar com o apoio de importantes pensadores da informação no contemporâneo, que compõem o Conselho Editorial da revista. Entendemos que sua aposta é ser este um momento oportuno para abertura de um canal específico para reflexões e diálogos filosóficos da informação e cuja confiança e apoio ao Comitê Editorial foi imprescindível:

André Luiz Martins Lemos, da Universidade Federal da Bahia - UFBA, engenheiro, mestre em Política de Ciência e Tecnologia e doutor em Sociologia pela Université René Descartes, Paris V, tem um caminho de pesquisas sobre a comunicação, especialmente a mediada por tecnologia e a cultura digital. Membro de diversas associações e conselhos nacionais e internacionais no âmbito de estudos das tecnologias digitais, mais recentemente inclina seu olhar, de um ponto de vista latouriano, sobre a "comunicação das coisas" por trocas automáticas de informação entre objetos reais e virtuais.

Delamar José Volpato Dutra, da Universidade Federal de Santa Catarina - UFSC, tem dupla formação, em direito e filosofia, e é doutor em filosofia pela UFRGS e seu tema central é a filosofia do direito. Seus interesses de pesquisa incluem o exame dos conceitos filosóficos que perpassam a fundamentação e aplicação do direito e sua relação com a moral, especialmente em Hobbes, Kant, Habermas, Schmitt, Hart e Dworkin. Atualmente dedica-se ao exame dos vínculos obrigacionais e ao exame dos fundamentos dos modelos contratualistas.

Flavio Beno Siebeneichler (Universidade Federal do Rio de Janeiro - UFRJ), filósofo e doutor em Teologia e Ciência da Religião pela Universidade de Regensburg, suas pesquisas, 


\section{EDITORIAL DE APRESENTAÇÃO}

de interesse ético-jurídico, lançam-se no exame da na razão comunicativa da filosofia pósmetafísica, da busca cooperativa da verdade e responsabilidade solidária, nas construções teóricas para sociedades pluralistas contemporâneas, tendo por bases a Teoria crítica e estética de Adorno, a Fenomenologia de Husserl e Ricoeur, a Hermenêutica gadameriana, a Teoria dos sistemas de Luhman e a Pragmática de Habermas e Apel.

Harry Kunneman, da Universiteit voor Humanistiek, na Holanda, tem formação em ciências sociais e doutorado em filosofia pela Universidade de Amsterdam. Sua perspectiva de humanismo crítico se alicerça no pensamento de Jürgen Habermas. Atualmente sua pesquisa coloca em foco questões de moralidade pós-moderna e a renovação do humanismo contemporâneo e os aspectos éticos das atuais tendências de configuração das pesquisas científicas.

José Augusto Chaves Guimarães, da Universidade Estadual Paulista - UNESP, formado em Biblioteconomia e em Direito, é mestre e doutor em Ciências da Comunicação pela USP e livre-docente em Análise Documentária pela Universidade Estadual Paulista. Suas pesquisas colocam questão entre teorias e práticas na organização da informação e do conhecimento e os aspectos éticos aí implicados. Tem realizado reflexões epistemológicas do campo e de questões da ética profissional e do uso ético e legal da informação digital.

Marta Macedo Kerr Pinheiro (Universidade Federal de Minas Gerais - UFMG) tem formação em Letras, é doutora em Ciência da pelo IBICT. Pós-doutorado em Ciência da Informação e da Comunicação pela Universidade Paul Sabatier/Toulouse III. Suas pesquisas focalizam as Políticas de Informação, o Estado Informacional, Inteligência de Estado e infoinclusão. Sua perspectiva de políticas e ações do Estado colocam questão sobre sua construção social.

Maria Nélida González de Gómez, do Instituto Brasileiro de Informação em Ciência e Tecnologia - IBICT e da Universidade Federal Fluminense - UFF, tem formação em filosofia e é doutora em Comunicação pelo IBICT. Coloca em exame questões contemporâneas da informação e da documentação, à luz das premissas filosóficas e epistemológicas. Suas pesquisas atuais, tomando a informação e documentação como modos de construção de evidência na sociedade moderna, indagam as relações entre o ciclo de vida da informação e 


\section{EDITORIAL DE APRESENTAÇÃO}

sua manifestação e efeitos na produção, legitimação e aferimento da validade dos conhecimentos, e algumas das condições e consequências, ético-políticas, dessa constituição.

Ralph Ings Bannell, da Pontifícia Universidade Católica do Rio de Janeiro - PUC-RJ, é filósofo e mestre e doutor em "Pensamento Social e Político" pela University of Sussex. Com enfoque na Filosofia da Educação, tem examinado as relações entre educação e racionalidade; educação, ética e política; entre a hermenêutica filosófica e a educação; o marxismo e a educação; a educação, a cultura e a comunicação; e a cognição e aprendizagem; linguagem, ação e mente.

Valéria Cristina Lopes Wilke, da Universidade Federal do Estado do Rio de Janeiro UNIRIO, é formada em Comunicação e Filosofia, mestre em Filosofia pela UFRJ e doutora em Ciência da Informação pelo IBICT. Em suas pesquisas tem colocado olhar privilegiado na Filosofia da Informação a partir da teoria do conhecimento, da história e filosofia da ciência. Suas atuais pesquisas colocam em relevo o paradigma informacional que perpassa a sociedade contemporânea, examinando aspectos ontológicos e epistemológicos da informação.

\section{Referências}

CAPURRO, Rafael. O conceito de informação. Perspectivas em Ciência da Informação, v.12, n. 1, p. 148-207, jan/abril, 2007.

HOFKIRCHNER, Wolfgrand (Org.). The quest for a unified theory of information. INTERNATIONAL CONFERENCE ON THE FOUNDATIONS OF INFORMATION SCIENCE, 2., 1000, Amsterdam. Proceedings... Amsterdam: Gordon and Breach Publishers, 1999.

GONZÁLEZ DE GÓMEZ, Maria Nélida. Para uma reflexão epistemológica acerca da Ciência da Informação. Perspectivas em Ciência da Informação, Belo Horizonte, v.6, n.1, p. 5-18, 2001.

JESUÍNO, José Correia. Processos cognitivos. In: Enciclopédia Einaudi. Diretor: Riggiero Romano. Edição Portuguesa: coordenador-responsável Fernando Gil. Lisboa: Imprensa Nacional - Casa da Moeda, 2000. v. 34.

MACHLUP, Fritz; MANSFIELD, Una. The study of information: interdisciplinary messages. New York: John Wiley \& Sons, 1983. 
